\title{
ÉTICA JUDICIAL E INTERPRETACIÓN JURÍDICA
}

\author{
Rodolfo Luis Vigo
}

RESUMEN. La superación del juridicismo y de la aplicación mecánica de las normas reclama un nuevo perfil de juez que no sólo atienda al conocimiento y habilidades jurídicas sino también a consideraciones éticas. En este marco, el autor aborda el tema de la ética judicial entendiéndola como un conjunto de comportamientos necesarios para la satisfacción de intereses comprometidos con el ejercicio de la actividad judicial y para la aceptación de las decisiones por parte de sus destinatarios. Procurando establecer el perfil del mejor juez históricamente determinado, el autor enuncia y desarrolla una detallada nómina de las exigencias éticas judiciales que permitan generar las mejores condiciones para garantizar la calidad del trabajo judicial.

Palabras clave: discrecionalidad, interpretación, ética judicial.

ABSTRACT. The superseding of legalism and of the mechanical application of norms calls for judges with a new profile, not only able to deal with knowledge and legal skills, but also with ethical considerations. In this context, the author approaches the subject of judicial ethics, which he understands as a set of actions necessary for the satisfaction of interests linked to the exercise of judicial activity and for the acceptance of decisions by those to whom they are addressed. In an attempt to establish the profile of the best historically determined judge, the author proposes and develops a detailed list of the judicial ethical requirements which make possible the best conditions in order to guarantee the quality of judicial work.

Keywords: discrecionality, interpretation, judicial ethics. 


\section{DEL JURIDICISMO Y LA APLICACIÓN MECÁNICA DE LA NORMA LEGAL, A LA MORALIZACIÓN DEL DERECHO Y LA CREACIÓN INTERPRETATIVA}

a vinculación entre la ética y la actividad judicial no es una tesis defendida pacíficamente. Entre sus detractores están fundamentalmente aquellos que postulan que al juez, para cumplir con la función que se le ha encomendado, le basta con conocer el Derecho y decirlo silogísticamente para cada caso. Desde esa perspectiva es perfectamente posible y no ofrece ninguna dificultad, que alguien sea una "mala persona" desde el punto de vista de una moral crítica o social, y al mismo tiempo sea un "buen juez". Por supuesto que el modelo de teoría jurídica decimonónica europea (forjado y auspiciado por la exégesis francesa, SAVIGNY y el primer IHERING) confía - en sintonía con MONTESQUIEU - en un "juez inanimado" que sea boca de la ley para cada caso y, por consiguiente, su tarea era totalmente objetiva y aséptica en tanto se limitaba a identificar la norma legal en la que podía subsumir en su hipótesis fáctica el caso que debía resolver y deducir la respectiva consecuencia jurídica prevista en aquélla. En ese paradigma, como es suficientemente sabido, las soluciones jurídicas las brindaba en exclusividad el legislador y a tenor de la presunción de un «legislador plena y perfectamente racional» la tarea judicial carecía de toda dimensión creadora y se reducía a transitar formalmente el camino del silogismo. Recordemos que el objeto de la interpretación jurídica era «reconstruir el pensamiento del legislador ínsito en la ley» (SAVIGNY) o, más vulgarmente, «desentrañar el sentido de la ley según lo pretendido por el legislador»; y a tales fines debía valerse de los métodos interpretativos (gramatical, lógico, sistemático e histórico) que aseguraban un cumplimiento fiel del juzgador a su mandato. El momento creador del Derecho se subsumía en la "voluntad del legislador" y luego el modelo de saber jurídico se ceñía a los postulados propios de la ciencia físico-matemática que se limitaba a describir y sistematizar sin ningún compromiso con valores. También recordemos que el modelo político europeo decimonónico reforzaba ese cumplimiento con la amenaza penal al juez que se apartaba del sentido de la ley, dado que tal comportamiento se tipificaba con el delito de prevaricato. En definitiva, al "voluntarismo" del legislador europeo fuera de cualquier control de racionalidad y capaz de juridizar cualquier contenido en tanto previsto dentro de la ley, le seguía la tarea del doctrinario y del juez que se circunscribía a un saber "teórico" en tanto pretendía una descripción absolutamente objetiva y sin preferencias axiológicas de aquel contenido legal ${ }^{1}$.

Por supuesto que la perspectiva "juridicista" implícita en el referido paradigma decimonónico fue puesta en crisis a lo largo de la segunda mitad del siglo Xx y, particularmente, al hilo del movimiento rehabilitador de la razón práctica. En efecto, aquella pretensión de que era posible entender y operar el Derecho sólo con Derecho, o sea, sin apertura a las dimensiones éticas, económicas, políticas, culturales, etc., terminaba diseñando un Derecho que más que reflejo de la realidad se convertía en una especie de caricatura de la misma. Es que el Derecho es inescindiblemente ético o moral ${ }^{2}$, de manera que cualquier comprensión del mismo que margine esa dimen-

\footnotetext{
${ }^{1}$ Cfr. mi libro de 1999: Interpretación Jurídica (del modelo iuspositivista legalista decimonónico a las nuevas perspectivas), Santa Fe: Rubinzal-Culzoni.

2 Contundemente escribe Robert Alexy: «el problema central de la polémica acerca del concepto de derecho es la relación entre derecho y moral. A pesar de una discusión de más de dos mil años, siguen exis-
} 
sión estará condenada a hablar de un Derecho sin correspondencia con la realidad jurídica o de un Derecho que puede volverse groseramente contra el mismo hombre. Esa carga ineludible ética o moral del Derecho ha recibido distintos nombres: así el tradicional de "Derecho natural" ("dikaion physikon" o "ius naturae") o los más actuales de "principios" («exigencias de justicia, equidad u otra dimensión de la moral» en DWORKIN), «derechos humanos» o «moral rights» (NINO), «bienes o valores humanos básicos» (FInNIS), «umbral de injusticia o injusticia extrema» (ALEXY) o «equidad» (RAWLS). Pero ese «coto indisponible o vedado» (GARZÓN VALDÉS) no queda como un mero postulado teórico sino que se proyecta al campo operativo propio de los juristas de muy diversas formas: así, por ejemplo, a la hora de analizar la validez y consiguiente obligatoriedad de las normas jurídicas en tanto aquella dimensión ética exigía no sólo comprobar la satisfacción del cumplimiento de los requisitos previstos en el sistema jurídico positivo sino también confirmar su conformidad a ciertas exigencias "éticas o morales". La fórmula de «la injusticia extrema no es derecho», propuesta por RADBRUCH y difundida por ALEXY ${ }^{3}$, resume en buena medida aquel rechazo al juridicismo y una asunción de la dimensión ética que hoy distintas corrientes pregonan respecto al Derecho. Por supuesto que el Estado Constitucional de Derecho que sucedió al Estado Legal de Derecho también ha contribuido decididamente a superar aquel modelo de ciencia jurídica de saber teórico cuyo paradigma eran las ciencias físico-matemáticas, y a afrontar el desafío de un saber jurídico práctico que inevitablemente apele a valores y que debe resignarse a certezas excepcionables ligadas a la prudencia y a la contingencia de los $\operatorname{casos}^{4}$.

Esa moralización, eticidad, principialismo, constitucionalización o humanización del Derecho no sólo ha puesto en crisis el juridicismo del modelo decimonónico sino también a su misma teoría jurídica interpretativa, que postulaba jueces inanimados sometidos a la única solución prevista en la ley que debían aplicar dogmática y silogísticamente a cada caso. Roto el espejismo juridicista se advierte que el Derecho es indisolublemente ético y que la alternativa de su "purificación" supone desfigurarlo hasta hacerlo irreconocible o asumir el riesgo de su des-humanización. Ese juego de valores, principios, derechos fundamentales o naturales implica cierta indeterminación acentuada, porque en definitiva pone al desnudo la posibilidad de una pluralidad de respuestas jurídicas frente al mismo caso según que el intérprete ponga el acento en uno u otro de los elementos axiológicos presentes en el Derecho. Es que la aplicación de estos últimos conlleva que el intérprete deba construir o reconstruir un juicio normativo que será la premisa mayor de su silogismo práctico en orden a la solución del caso, dado que sólo a través de esa mediación normativa se puede resolver o concluir una norma para ese particular caso en base a aquel principio o valor o Derecho natural. Así por ejemplo el principio de buena fe tiene muy variadas proyeccio-

\footnotetext{
tiendo dos posiciones básicas: la positivista y la no positivista» (de 1997: El concepto y la validez del derecho, Barcelona: Gedisa, p. 13), y también concluye Francisco LAPORTA: «el problema de las relaciones entre moral y derecho no es un tema de la filosofía jurídica, sino que es el lugar donde la filosofía del derecho está» (de 1993: Entre el derecho y la moral, México: Fontamara, p. 7).

${ }^{3}$ Cfr. mi libro de 2004: La injusticia extrema no es derecho (de Radbruch a Alexy), Facultad de DerechoUniversidad de Buenos Aires y La Ley.

${ }^{4}$ Cfr. Zagrebelsky, G., 1997: El derecho dúctil, Madrid: Trotta, y Carbonell, M., 2003: Neoconstitucionalismo, Madrid: Trotta.
} 
nes posibles en las más diversas materias (laboral, procesal, contractual, relaciones internacionales, etc.), pero si el intérprete pretende resolver un caso concreto invocando dicho principio deberá construir una norma en donde pueda subsumirse dicho caso. Según las clásicas reglas del silogismo se requiere de tres términos: mayor, menor y medio, y así mientras en la premisa mayor se incluyen el mayor y el medio, en la premisa menor aparecerán el término menor y se repite el medio que es el que garantiza la conexión entre las premisas y la respectiva conclusión. Precisamente los principios, valores o derechos carecen de esa estructura propia de los juicios, por eso el intérprete debe explicitar o construir uno en base a algunos de aquéllos y así habilitar la posibilidad de transitar un silogismo práctico (no teórico) en donde pueda subsumirse en la hipótesis fáctica de la premisa mayor el caso que debe resolver aplicándole las consecuencias respectivas. En definitiva, la presencia de esos elementos éticos pone en juego una teoría interpretativa que partiendo de la indeterminación del principio o valor apela a la formulación de una norma por parte del intérprete en donde resulte subsumible el caso, todo lo cual torna absolutamente inviable el objeto de la decimonónica teoría interpretativa («desentrañar el sentido de la norma») y los cuatro métodos interpretativos postulados por SAVIGNY.

La referida indeterminación y moralización que conllevan valores, principios o eticidad y la consiguiente creación jurídica por parte del intérprete exige la superación del juridicismo y la ficción de que para cada caso había una solución proporcionada por el legislador. Más aún, esa crisis del juridicismo se acentúa cuando se advierte con la escuela hermenéutica que el enunciado normativo general sin el caso que regula está incompleto, por eso sólo con éste puedo comprender el significado de aquél. El intérprete crea en base a los principios, valores o derechos fundamentales el enunciado normativo o la norma general o universal en donde se subsumirá el caso, precisamente ese precedente será objeto de vivo interés por parte de los operadores del Derecho a los fines de prever la solución que tendrán sus casos análogos, y por eso la necesidad de su publicidad o difusión de la jurisprudencia haciéndola conocer a los juristas fundamentalmente a través de las revistas especializadas. Pero ese protagonismo creativo del intérprete se ve agravado si pensamos que habitualmente frente a un caso aparece la posibilidad de recurrir a más de un principio, valor o derecho humano, lo que supone enfrentar el problema del «conflictivismo de principios o derechos fundamentales» ${ }^{5}$. En torno a este problema interpretativo aparecen distintas propuestas ${ }^{6}$ : básicamente aquella que plantea una jerarquización apriorística de los principios que guíe la opción del intérprete (DWORKIN), la propuesta consolidada en la jurisprudencia norteamericana de "check and balances" que obliga al intérprete a ponderar los principios y las respectivas soluciones en tensión, y la propuesta de raigambre constitucional alemana que confía en la superación del conflicto a través de una apropiada definición del "contenido esencial" de cada uno de los derechos o de los valores o principios en juego que evita el "darwinismo" de principios $^{7}$.

5 Cfr. Cianciardo, J., 2000: El conflictivismo en los derechos fundamenales, Pamplona: EUNSA, y SeRnA, P., y TOLLER, F., 2000: La interpretación constitucional de los derechos fundamentales, Buenos Aires: La Ley.

${ }^{6}$ Cfr. mi libro de 2000: Los principios jurídicos, Buenos Aires: Depalma.

Cfr. las obras citadas en la nota 5. 
Más allá de propuestas teóricas, lo que queda consentido es la presencia normalmente de varias respuestas jurídicas que el intérprete puede encontrar en el Derecho vigente. En efecto, frente a la confianza decimonónica de "una" y "sólo una" respuesta jurídica para cada caso, se acepta la alternativa de más de una respuesta para el mismo caso como lo refleja la jurisprudencia contradictoria y los votos mayoritarios y minoritarios de los fallos. Seguramente resultaría disparatado, amén de improcedente, acusar del delito de prevaricato a alguno de los jueces responsables de esas diferentes respuestas jurisprudenciales, no obstante que en estricta lógica decimonónica habría que suponer que alguna de ellas se apartó del «sentido de la ley» porque de lo contrario entraría en crisis la «presunción del legislador racional». Ejemplificando lo que llevamos dicho con el art. 43 del Estatuto del Juez Iberoamericano que aprobaran las 22 Cortes Supremas de Iberoamérica en Canarias en 2001, puede constatarse que ahí se indica a los jueces fallar teniendo siempre presente el trasfondo humano de dichos conflictos "y procurando" atemperar con criterios de equidad las consecuencias personales, familiares y sociales desfavorables; pero puede ocurrir que no resulten coincidentes las soluciones judiciales según se basen en una u otra de esas consecuencias, por lo que sólo cabe el recurso a la discrecionalidad judicial que deberá optar por alguna de aquellas posibles derivadas todas ellas del Derecho vigente.

\section{LA ÉTICA FRENTE A LA INELUDIBLE DISCRECIONALIDAD JUDICIAL}

El punto anterior ha permitido concluir en la hoy visible y creciente creación jurisprudencial, lo cual termina potenciando la importancia y trascendencia de la actividad judicial. Esa judicialización de la vida social genera inexorablemente un Poder Judicial muy activo y presente que incluso tiene encomendada la poderosa misión de hablar en última instancia en nombre del poder constituyente. Por ese camino se tensa la división de poderes, pero sobre todo se pone en riesgo la previsibilidad jurídica a la que aspiran legítimamente todos los destinatarios del Derecho vigente. No se trata de auspiciar una seguridad jurídica ficticia e imposible a tenor de la referida moralización o principialismo jurídico y la importancia que tienen los contingentes hechos. Pero tampoco se trata de renunciar a la previsibilidad posible y confiar dogmáticamente en la solución que sólo conoce el juez que decidirá el caso. Precisamente frente a esa inevitable discrecionalidad uno de los remedios lo constituye la ética judicial. De esa derivación final en la ética del juzgador también se hace cargo Perfecto ANDRÉs IBÁÑEZ cuando afirma: «la legitimación del juez es legal, pero la forma necesariamente imperfecta en que se produce su sujeción a la ley, tiñe de cierta inevitable ilegitimidad las decisiones judiciales (FERRAJOLI), en la medida en que el emisor pone en ellas siempre algo que excede del marco normativo y que es de su propio bagaje; creo que una última exigencia ética dirigida al juez de este modelo constitucional es que debe ser muy consciente de ese dato, para ponerse en condiciones de extremar el (auto) control de ese plus de potestad de decidir» ${ }^{8}$. Por supuesto que la ética judicial no es

${ }^{8}$ ANDRÉs IbÁÑez, P., de «Ética de la función de juzgar», en 2001: Ética de las profesiones jurídicas, FeRnández Fernández, J. L. y Hortal Alonso, A., Madrid: Universidad Pontificia de Comillas, pp. 79-80. 
la única alternativa a la discrecionalidad (por ejemplo resultan importantes también las teorías que apelan a la argumentación jurídica), pero es a ella a la que queremos referirnos ahora.

Aunque resulte extraño o paradojal recordemos que la ética judicial como sucedáneo de la discrecionalidad judicial es una tesis que defendió HART al afirmar: «en este punto los jueces pueden hacer una elección que no es arbitraria ni mecánica; y aquí suelen desplegar virtudes judiciales características que son especialmente peculiares de la decisión jurídica, lo que explica por qué algunos se resisten a calificar de legislativa a tal actividad judicial. Estas virtudes son: imparcialidad y neutralidad al examinar las alternativas; consideración de los intereses de todos los afectados; y una preocupación por desarrollar algún principio general aceptable como base razonada de la decisión»? También va a hablar de virtudes judiciales Manuel ATIENZA «como ciertos rasgos de carácter que deberían poseer —y quizá posean- los jueces» que posibilitan cierta anticipación o previsibilidad de las soluciones jurídicas para los casos concretos ${ }^{10}$. El catedrático de Alicante, apoyándose en MACINTYRE, vincula el "buen juez" con esas virtudes judiciales en cuanto cualidades adquiridas cuya posesión y ejercicio posibilitan modelos de excelencia y la obtención de ciertos bienes internos para toda la comunidad que participa en la práctica del derecho. El núcleo de la tesis acerca de las virtudes judiciales es que hay ciertos rasgos adquiridos en el carácter o la personalidad de algunas personas que los hacen más idóneos para cumplir la función judicial; aunque aclara ATIENZA que «las virtudes de los jueces no pueden ser muy distintas de las que caracterizan a otras profesiones o prácticas sociales (...) las virtudes básicas (las virtudes cardinales de origen griego) reciben una cierta modulación en razón de las peculiaridades de la práctica judicial» ${ }^{11}$. Esas personas que tienen un modo habitual de decidir, comportarse, de hablar, de pensar, de escuchar, de razonar, de conducir a otros, de enfrentar dificultades, etc., lo que constituye una especie de personalidad ética que permite suponer que van a cumplir la función del modo más perfecto posible o también permite suponer que los destinatarios de sus decisiones la aceptarán más fácilmente en razón de esas cualidades y calidades personales. Esas presunciones juris tantum tienen que ver con los requerimientos de la actividad judicial misma y con la visión de aquellos a los que se dirige dicha actividad judicial. Así por ejemplo si el juez debe «decir el Derecho» ello exige que lo conozca, por eso el hecho que ese juez efectivamente esté en posesión del conocimiento jurídico permite suponer que cuando hable dirá el Derecho y los destinatarios confiarán que lo que le asignan jurídicamente es lo que corresponde según el Derecho; si por el contrario es visible su ignorancia jurídica será prácticamente imposible que pueda decir el Derecho y sus pronunciamientos padecerán de un rechazo o presunción en contrario de su validez. Dicho lo mismo aunque de manera más completa y categórica: la ética judicial y sus exigencias tienen que ver con ciertos bienes o intereses en juego en la tarea judicial, de manera que según la calidad con la que ésta es prestada o ejercida aquellos bienes, intereses o perfecciones serán satisfechos

\footnotetext{
9 Hart, H., El concepto de derecho, Buenos Aires: Abeledo Perrot, p. 253.

${ }^{10}$ Cfr. Atienza, M., 2004: «Virtudes Judiciales. Sobre la selección y formación de los jueces en el Estado de derecho», en Jueces y Derecho, México: Porrúa-Universidad Nacional Autónoma de México, pp. 17 y ss.

${ }^{11}$ Atienza, M., 2001: «Ética judicial», en Cuestiones judiciales, México: Fontamara, p. 153.
} 
o perjudicados en mayor o menor medida. Esos bienes y sus respectivos titulares reclaman ciertos comportamientos o hábitos para posibilitar o facilitar su cobertura o para aventar sospechas o para aceptar la discrecionalidad judicial. Los deberes negativos o positivos incluidos en la ética judicial son parasitarios de esos bienes, a punto que si uno no ve la relación entre aquéllos y los bienes en juego en la tarea judicial puede concluirse que esos deberes no están justificados racionalmente. El criterio de justificación racional de los deberes o exigencias éticas lo marcan los bienes comprometidos en la actividad del juez, por eso resulta inapropiada la denominación "deontología judicial" en tanto ella apela etimológicamente a un catálogo de deberes $($ deon $=$ deber $)$, mientras que la ética remite a esos bienes que hay que procurar alcanzar ${ }^{12}$.

Resumiendo, podemos decir que la ética judicial requiere de ciertos comportamientos, aún mejor, de una cierta personalidad o idoneidad ética; pues hablamos de comportamientos o hábitos que presumiblemente facilitan o se necesitan para la obtención de los bienes comprometidos en esa actividad o que favorecen la aceptación de las decisiones judiciales fruto de cierta discrecionalidad por parte de sus destinatarios. Para decirlo en negativo: la ausencia de esa personalidad o idoneidad ética, o sea, esos comportamientos o hábitos opuestos a aquéllos comprometen ab initio esa posibilidad, presunción o aceptación de los destinatarios.

\section{LOS BIENES QUE FUNDAN LAS EXIGENCIAS ÉTICAS JUDICIALES}

Recordemos que contemporáneamente el juez cumple un servicio remunerado que le ha encomendado la sociedad, la que además le ha otorgado un cierto poder o imperio y le ha puesto a su disposición el auxilio de ciertos colaboradores, pero todo ello para derivar racionalmente desde todo el Derecho la solución justa que corresponde determinar para los casos que han sido asignados a su jurisdicción. Recalquemos algo ya dicho: derivación de la razón práctica que incluye cierta indeterminación o discrecionalidad judicial. Según esa tarea se cumpla bien o mal, mejor o peor, va a ver ciertos bienes satisfechos, insatisfechos o perjudicados. La noción de bien se asocia analógicamente a perfección, excelencia, completitud o acabamiento y, en consecuencia, podemos identificar diversos bienes o intereses o perfecciones implicados en la tarea judicial, a saber: el bien de los justiciables, el bien de la sociedad, de los abogados, el bien de los colegas, el bien de los auxiliares, el propio bien del juez implicado y el bien del Derecho. En definitiva, las consecuencias de un buen, mal o mediocre juez impactan directamente sobre algunos o todos esos bienes y, consecuentemente, resultarán beneficios o perjuicios. Esos resultados de la actividad judicial que se traducen en perfecciones o frustraciones generarán, consiguientemente, una mejor o peor situación, lo que conllevará felicidades o realizaciones, o frustraciones o infelicidades en relación directa a los mismos resultados. Por detrás de una exigencia ética hay siempre alguien que espera o algo que resulta para "bien" o para "mal", lo cual será fuente

12 «La ética profesional se centra ante todo en el tema del bien. Sin la perspectiva ética, la deontología se queda sin horizonte de referencia», Fernández Fernández, J. L., Hortal Alonso, A., 1994: Ética de las profesiones, Madrid: Universidad Pontificia de Comillas, p. 57. 
de felicidad, gozo o infelicidad o lamento ${ }^{13}$. Este resultado muchas veces es racional u objetivo pero, en otras, la certeza probable o excepcionable que provoca se ve corroborada o puesta en duda, la que en buena medida se despeja o se agrava en base a la confianza o desconfianza que suscita el agente responsable de la decisión. Advirtamos que esa confianza o desconfianza de los destinatarios judiciales, si bien puede ser irrazonable o patológica, también puede ser razonable o justificada. Será razonable o justificada cuando se apoya en exigencias reclamadas al juez que tienen que ver con las características de esa función, y con la mejor o peor disposición para cumplirla del modo más completo posible aventando las dudas respectivas.

Ejemplificando lo dicho en el párrafo anterior con la exigencia ética del «conocimiento del Derecho» podemos visualizar los bienes comprometidos en la misma según el listado de bienes o destinatarios señalado arriba. Indiquemos en primer lugar el bien de las partes que pueden confiar o presumir que lo dicho por el juez es efectivamente el Derecho dado que les consta su conocimiento aquilatado, e incluso esa autoridad académica que inviste el juez les hace aventar desconfianza o les facilita la aceptación de lo dicho como Derecho. Pero además del bien de las partes, también el de los abogados está presente dado que argumentar jurídicamente frente a un juez ignorante o no actualizado sobre el Derecho aplicable es casi una pérdida de tiempo o un esfuerzo inútil. El bien de la sociedad, en tanto sus miembros o las autoridades pueden esperar confiadamente si algún día les toca ir a los tribunales dado que los jueces conocen el Derecho, y también porque se evitan gastos innecesarios o se genera la confianza indispensable como para que la economía funcione apropiadamente. El bien de los colegas, dado que el juez ignorante proyecta su descalificación o falta de confianza sobre los otros colegas atento a que los ámbitos profesionales generan un cierto bien corporativo o sectorial que se construye, protege o potencia entre sus integrantes y lo que hace uno repercute de alguna manera en los otros. El propio bien del juez, atento que al exigírsele conocimiento jurídico se está favoreciendo su autoestima, prestigio o reconocimiento que deriva de esa capacitación, amén de evitarle eventuales perjuicios, frustraciones o inquietudes por interrogantes sin respuestas. El bien de los auxiliares en tanto ellos también se benefician o perjudican según presten servicios a jueces ignorantes o capacitados en el Derecho. Finalmente, el bien del Derecho, dado que analógicamente también él resulta mejorado o empeorado según lo opere un juez capacitado o ignorante del Derecho.

Esas exigencias éticas que apuntan a la persona del juez se determinan en orden a lograr el mejor o más excelente juez para esa sociedad de ese tiempo y lugar. Es ésta la perspectiva formal de la ética judicial: el mejor juez históricamente determinado. En aquellas exigencias habrá algunas universales (por ejemplo: independencia) en tanto son constitutivas de la esencia misma de ser juez, aunque no se excluye el contenido histórico que ellas legítimamente asumen sin violentar los respectivos núcleos constitutivos o definicionales. Pero además de exigencias universales hay otras totalmente contingentes que se explican en función de tiempo y lugar, por ejemplo, establecer el requerimiento de una cierta "austeridad republicana" para los jueces argentinos de la

13 Resultan muy interesantes las explicaciones de Antonio MiLláN-PUELLES en torno a lo que llama las tres condiciones una ética realista: el amor de sí mismo, la búsqueda de la felicidad y el placer (de 1996: Ética y realismo, Madrid: Rialp, p. 32). 
actualidad replicando lo previsto en la ley de ética de la función pública. Remitirnos al "mejor juez" implica pensar en que lo que ellos hacen resulte ser lo más perfecto posible, por eso las exigencias éticas pretenden generar las condiciones para que se logre aquel completo resultado y se evite suscitar temores sobre la calidad del trabajo judicial. Logrando por el camino de la ética judicial el "mejor" juez posible, los bienes o intereses implicados quedarán cubiertos o satisfechos.

La ética judicial al pretender el mejor juez no sólo rechaza el "mal juez" sino también el "juez mediocre", o sea, no sólo aquel que hace lo contrario de lo exigido sino aquel que lo cumple en menor medida de lo que él podría o se pretende. Siguiendo con el ejemplo del conocimiento del Derecho, es obvio que el mismo se puede satisfacer de manera muy diferente, y así no sólo encontraremos el que ignora el Derecho sino también aquel que no se esfuerza en conocerlo y se limita a consultar sólo a alguna fuente doctrinaria porque está a su fácil alcance. La ética reclama vocación de excelencia o magnanimidad, y por sobre la decisión personal del juez, ella está implícita o requerida en el mandato otorgado por la sociedad para cumplir con su importante tarea que la lleve a cabo del mejor modo. Seguramente la sociedad no le brindaría ese poder a quien confiese inicialmente que lo cumplirá mal o mediocremente; por eso, no seguir la ética es un modo de defraudar aquella condición implícita que conlleva el privilegio de la función.

\section{UNA NÓMINA DE LAS EXIGENCIAS ÉTICAS JUDICIALES}

Conforme a lo señalado, el objeto material de la ética judicial será el juez, y la definición de quién y cómo efectivamente se alcanza la función judicial es un tema que nos remite al Derecho y a la cultura de cada sociedad (así por ejemplo: qué edad se exige, qué conocimientos, quién designa, etc.). El objeto formal de la ética judicial es qué le exigimos a ese juez para que llegue ser el "mejor"; se trata de exigencias que constituyen pre-requisitos o condiciones para esa excelencia y también exigencias que se vinculan a un modo apropiado de cumplir la actividad; el hecho de que el juez cuente o satisfaga esas exigencias genera presunciones de excelencia a favor de la actividad cumplida por el mismo, amén de ponerlo en posesión de aquella capacidad para cumplirla excelentemente, y así logra cierta "autoridad" que facilita la aceptación de sus decisiones. El justificativo principal de esas exigencias son los bienes o intereses implicados, aunque su racionalidad también descanse en cierta antropología o psicología apoyada en la experiencia humana consolidada. Son precisamente esos bienes los que se constituyen en los fines mismos de la actividad judicial, de donde su insatisfacción genera lo que en la terminología de MACINTYRE se llama "corrupción", dado que se estaría prestando la función no buscando los fines que justificaron su creación legítima sino poniéndola al servicio de fines externos a la misma como el placer, el dinero o la fama ${ }^{14}$. De todas maneras, en la ética judicial, como en cualquier ética profesional, será inevitable el discurrir por exigencias muy generales cuya aplicación concreta puede generar mil particularidades, por eso, a los fines de cubrir esa distancia

${ }^{14}$ Cfr. CoRtina, A., 1996: «La regeneración moral de la sociedad y de la vida política», en Corrupción y ética, Bilbao: Cuadernos de Teología Deusto. 
entre lo general y lo concreto y cubrir las inquietantes indeterminaciones de las exigencias en sus destinatarios, existe la posibilidad de establecer Comités u Órganos de consultas para las dudas éticas. Precisamente, los interesados, que nunca serán buenos jueces en propia causa ética, tienen la posibilidad de recurrir a ellos para plantear anónimamente sus incertidumbres en torno al comportamiento que corresponde adoptar éticamente, y así despejar dudas y cubrirse por eventuales futuros problemas.

\subsection{Independencia}

Toda ética profesional requiere que el profesional preste su servicio según su ciencia y conciencia; en consecuencia, resulta incompatible la misma con un profesional que aparezca sometido a las directivas del cliente mientras presta su trabajo. No se trata del deber de informar lo que se va a hacer, sino que aceptado el servicio y sus características, estará en manos del profesional la prestación del mismo. En el caso del juez lo que se pretende es que él y sólo él sea quien derive desde el Derecho la solución justa para el caso, o sea, se reclama la auto-determinación judicial en cuanto no hay un tercero que le indique qué debe decir en el proceso o en su sentencia. Dado que estamos hablando de ética judicial, concentraremos nuestra atención en la independencia subjetiva o personal y, en consecuencia, no aludiremos a esa otra dimensión de la independencia que es la estructural, institucional u objetiva, o sea, a las definiciones en torno a las relaciones entre el poder judicial y los otros poderes; al modo en que se designa, sanciona o destituye al juez; al presupuesto judicial; al nivel remuneratorio; etc. En la conciencia social de nuestros días quizás el mayor riesgo para que la reclamada independencia se vincule al Poder político, en tanto se puede suponer que el mismo ejerce una influencia decisiva sobre el juez atento a que lo ha constituido como tal, le permite mantenerse en la función o lo puede remover. Sin embargo, en ese terreno de la independencia subjetiva o personal hoy existe una difundida opinión entre los jueces de que uno de los mayores desafíos a su independencia es el poder de los medios de comunicación social capaces de generar en la población la convicción acerca de ciertas respuestas jurídicas, lo que luego torna tremendamente complicada la decisión judicial en tanto sea contraria a aquel prejuzgamiento periodístico.

En la presente exigencia ética como todas las restantes no sólo se pretende que un juez efectivamente la cumpla sino que también genere la impresión que ello es así; pues la ética judicial en función de los bienes o intereses comprometidos exige tanto el ser como el parecer. Entonces el juez, para decidir lo que éticamente le corresponde hacer, no sólo debe atender a su conciencia sino también a las posibles lecturas que los otros harán de su comportamiento. Además también vale para esta y las restantes exigencias que cuando la ética judicial impone un deber está implícito el derecho de exigir la posibilidad de cumplir con el mismo, y es desde esta lógica bifronte que el Estatuto del Juez Iberoamericano contempla el derecho de un juez amenazado a pedir al Estado protección policial.

Considerando algunos problemas éticos específicos, mencionemos el de la relación de los jueces con los partidos políticos. En particular aparece la cuestión de la afiliación a los mismos, y la indicación ética al respecto es que el juez no sólo suprima toda relación con los partidos, sino que suspenda su afiliación o, mejor aún, se des- 
afilie como un gesto simbólico de compromiso público con la independencia. Esa desvinculación es hacia las instituciones partidarias, pero también hacia las personas o dirigentes políticos que las representan.

\subsection{Imparcialidad}

El juez por definición es un tercero equidistante respecto a las partes que traen su problema jurídico para que lo resuelva. Esta exigencia guarda relación con la anterior aunque apunta a una de las características de la función judicial en la que hay partes enfrentadas en su reclamo. La humanidad dio un gran salto civilizador o racional cuando abandonó la resolución de los problemas jurídicos a través de la fuerza, la astucia o el azar y los puso a tales fines en manos de un tercero imparcial. Es contraintuitivo suponer que alguien pueda consentir que su caso sea resuelto por un amigo de la contraparte, más bien lo evidente es que pretenda la intervención de un imparcial tanto en la realidad como en las apariencias. La respuesta jurídica a la reclamada imparcialidad transita por el camino de las excusaciones y recusaciones, aunque hay causales más vinculadas a la interioridad del juez (por ejemplo, la violencia moral) que resultan difíciles de ser controladas y que en consecuencia requieren de un manejo ético no abusivo por parte de quien la invoca.

Entre los problemas éticos que conlleva la imparcialidad está el modo éticamente tolerado o aconsejado de reunirse el juez con las partes y/o sus abogados. Al respecto son posibles distintas propuestas, por ejemplo las siguientes: 1 . Que se rechace la posibilidad de esas reuniones atento a que si alguna parte o abogado tiene algo para decir al juez lo debe hacer por medio de un escrito o a través de la secretaría. 2. La reunión sólo puede efectuarse en la medida que comparezcan ambas partes o abogados (solución adoptada por la Corte Suprema nacional). 3. La parte interesada en la reunión efectúa el pedido por escrito, el que es resuelto por el juez previa vista a la contraparte. 4. El juez puede recibir a una de las partes pero luego debe notificar de tal entrevista a la contraparte ofreciéndole un trato equivalente. 5 . El juez recibe a quien lo solicita pero en su despacho y en presencia de un colega o el secretario. Nos parece éticamente desaconsejable que el juez reciba a la parte sin el abogado apoderado.

Otro problema es el de los regalos. En principio cabe una respuesta negativa en torno a la posibilidad de los mismos al juez por parte de los litigantes. Sin embargo, puede haber situaciones complicadas; como por ejemplo cierta costumbre de regalar comestibles o bebidas con motivo de las fiestas de fin de año; o también el regalo del libro escrito por el abogado que litiga en ese juzgado; o asimismo el regalo para el día del cumpleaños del juez; etc. De todas maneras, el establecimiento de una norma ética precisa al respecto brinda la posibilidad de saber qué conducta adoptar y con ese respaldo evitar las molestias de abogados o eventuales incomprensiones por cambiar criterios que se venían aplicando.

Aquí, y también en la exigencia anterior, entra la cuestión del comportamiento judicial respecto a los medios de comunicación social. Más allá de la necesidad de informar y del derecho de los medios a recabar esa información, el juez debe ponderar otros intereses y, además, no puede incurrir ni dar la impresión de que hay un tratamiento desigual a las partes o existe una intencionalidad respecto a la causa judicial 
en trámite. Los Códigos de Ética judicial se han detenido en este punto dando algunas pautas específicas al respecto, así por ejemplo el de la provincia de Santa Fe en sus arts. 5.2 y 6.13, el de Costa Rica en los arts. 3 y 8 o el de Italia en el art. 6.

\subsection{Conocimiento}

Cualquier profesión supone un cierto conocimiento vinculado al servicio que se presta, y esa indicación ética también abarca al juez. En este caso advirtamos que no es sólo el conocimiento de la rama jurídica implicada en la competencia jurisdiccional respectiva, sino también el conocimiento del sustantivo "Derecho" a secas y de aquel Derecho requerido para cualquier juez, por ejemplo el constitucional, el humanitario, el de los derechos humanos, el internacional, la teoría interpretativa, etc. Pero también el conocimiento judicial requerible es acerca de ciertos saberes no estrictamente jurídicos referidos a los hechos que necesitan ser conocidos para decir el Derecho al respecto.

Más allá de la materia del conocimiento, una de las discusiones éticas es acerca de la capacitación obligatoria u optativa, y pareciera consolidarse la alternativa de la obligatoria: así, el Estatuto del Juez Iberoamericano la impone en casos de «ascensos, traslado que implique cambio de jurisdicción, reformas legales importantes y otras circunstancias especialmente calificadas» (art. 28). Incluso ese Estatuto en el art. 23 avanza sobre la posibilidad de imponer la capacitación judicial como «medida correctiva o disciplinaria». Por supuesto que aun cuando se establezca la capacitación como obligatoria siempre será razonable brindar la alternativa que se acredite estar capacitado como para evitar la asistencia innecesaria a los Cursos correspondientes.

Recordemos aquí que si existe el deber a la capacitación también cabe reconocer el derecho a reclamarla o recibirla, dado que la ética no puede exigir algo de imposible cumplimiento.

Un juez que ignora el Derecho no tiene capacidad para decirlo, o sea, carece de una específica para ser juez, por lo que pesarán sobre él todas las dudas en torno a cada una de sus decisiones, especialmente aquellas difíciles.

\subsection{Prudencia}

En una terminología clásica de ética profesional se habla de la ciencia y también de la conciencia, es decir, esta última apela a la capacidad como para operar con aquella ciencia determinando racionalmente la conducta que ella exige para cada caso. Así no basta para el buen médico que sea capaz de dar una clase sobre apendicitis sino que sea capaz de realizar la respectiva cirugía. En el caso del juez resulta particularmente visible su conexión con la prudencia en tanto su objeto coincide con el mismo objeto de la función judicial, es decir, determinar racionalmente la conducta justa debida o prohibida según el Derecho. Incluso esa conexión se revela en la misma terminología de la iuris-prudentia en tanto obra de los iuris prudentes.

La prudencia es mucho más que conocimiento, es —al decir de CiCERÓN- «el arte de vivir» y de vivir conforme al "bien” o lo mejor. En el campo de lo jurídico 
sería conocimiento en acción o proyectándolo en los casos concretos que requieren una respuesta jurídica. Pero a su vez desde la filosofía clásica esa capacidad racional acerca del bien en las cosas de la vida circunstanciada se la conecta con ciertas cualidades en el razonamiento o condiciones personales; así por ejemplo: 1. Experiencia: decía ARISTÓTELES que era posible encontrar un joven brillante en matemáticas pero era improbable que existiera en materia de prudencia, es que ésta requiere de haber vivido y la memoria respectiva. 2. Capacidad de diálogo: tratándose de conductas humanas donde la certeza no es absoluta, es importante contar con esa disposición a escuchar otros puntos de vista y poder ponderar razones. 3. Humildad: como para cambiar posturas y acudir a aquellos que más saben; quien cree estar en posesión absoluta de la verdad y sólo dispuesto a brindarla a los otros difícilmente llegará a ser prudente. 4. Circunspección: o sea, preocupación por leer detenida y completamente las circunstancias en las que se desenvuelve la conducta objeto de la prudencia. 5. Previsión: es que la prudencia requiere no sólo el caso en el que corresponde pronunciarse sino también las consecuencias que a partir del mismo se pueden derivar más allá del mismo. 6. Coherencia: la racionalidad está reñida con las incoherencias de toda índole, por ejemplo la lingüística, la lógica, la insinceridad, tratamiento desigual de lo igual. 7. Tiempo: en tanto seguramente no habrá razonamiento prudencial si no estamos dispuestos a disponer de un tiempo necesario para ello, pues los apresurados difícilmente serán prudentes; etc. Quien carece de esas condiciones para ser prudente deberá procurarlas, porque de lo contrario sus decisiones judiciales difícilmente serán prudentes y, por ende, resultarán imposibles sus posibilidades de excelencia.

\subsection{Justicia}

Al ser la medida de todos los actos buenos y de las virtudes respectivas, se requiere de la prudencia jurídica para discernir lo justo pero también se necesita el querer darlo. Conocida es la clasificación de las cuatro virtudes cardinales, y según ella la prudencia inhiere en la razón práctica y la justicia en la voluntad. Desde esta perspectiva hubiese bastado exigir prudencia dado que el juez estrictamente cumple una función de discernimiento racional, pero la justicia apela a ese "apetito espiritual" cuyo objeto es lo suyo de cada uno y el querer que éste sea recibido por su titular. Quien es justo seguramente cuenta con la mejor matriz para que la razón prudencial logre determinar lo justo en cada caso, por eso ARISTÓTELES llama al juez «justicia viviente o animada» (dikasterion) en tanto los hombres llevan a él sus diferencias porque están convencidos que «ir al juez es ir a la justicia» (EN 1132a: 19-22) ${ }^{15}$. Un juez prudente es capaz de decir lo justo, pero si además - precisa Tomás de AQUino- es justo lo dirá «con prontitud y agrado» (S. Th. I-II, 107, 4); en definitiva, quien quiere y logra la justicia en sus actos vive en un compromiso verdadero con el otro ${ }^{16}$.

Quizás un modo apropiado de recuperar esa exigencia ética de justicia para el juez es recordarle que tome conciencia de su función y quiera «determinar lo justo desde

${ }^{15}$ Cfr. García Maynez, E., 1984: «Imagen aristotélica del buen juez», en Ensayos Filosóficos-Jurídicos, Universidad Nacional Autónoma de México, pp. 389-398.

${ }^{16}$ Cfr. PIEPER, J., Las virtudes fundamentales, Madrid: Rialp, pp. 99 y ss. 
el derecho», por eso su preocupación para respetar y querer dar la justicia. Acertadamente insiste GABALDÓN LÓPEZ: «no cabe, pues, en el juez una actitud de neutralidad moral, porque las normas éticas le exigen una actuación que tienda a conseguir la justicia como meta de sus actos» ${ }^{17}$. Más aún, desde Antígona aparece el riesgo de que lo dispuesto por la autoridad sea injusto, y lo sea de una manera extrema y evidente, por eso quien debe decir el Derecho necesita de ese propósito de justicia. Seguramente quien no quiere dar lo justo o carece del hábito respectivo le costará asumir la tarea de discernimiento atento a que la razón humana no es algo desencarnado o desvinculado del apetito. En la confianza del ciudadano que asiste a un despacho judicial pesará de manera significativa cuál es la imagen que el juez se ha forjado en torno a la justicia, y no sólo mirada en términos jurídicos o judiciales, sino principalmente en cuanto a sus comportamientos como ciudadano respecto a lo que confiere o respeta de los demás.

No está de más recordar la dimensión analógica o los distintos modos de la justicia, por eso de ella se habla tanto en la distribución en beneficio de los particulares, en la conmutación que procura equivalencia en las contraprestaciones y en la imposición de débitos en beneficio del todo social, pero tratándose del juez sin olvidar que lo justo y lo equitativo son «ambos valiosos», es la equidad preferible en cuanto perfección de la justicia en función del caso en que se pronuncia el juicio prudencial del juez.

\subsection{Fortaleza}

En la visión clásica también era ésta una de las virtudes cardinales que tenía por objeto el "bien arduo" (bonum arduum) en tanto permite la adhesión al mismo resistiendo o asumiendo los riesgos respectivos. Hablando del juez aparece como evidente la exigencia de la fortaleza o valentía, en tanto un juez cobarde es susceptible de fácil pérdida de su independencia o imparcialidad. Por supuesto que no estamos hablando de temeridad, o sea, de alguien que busque o se deleite en el peligro, sino de aquel que es capaz de decir el Derecho que corresponde aun "con" miedo pero nunca "por" miedo.

Se trata de una exigencia ética íntimamente vinculada con un cierto talante psicológico frente a los riesgos y las incertidumbres, que reclama el perseverar a pesar de los mismos y también el enfrentarlos. Seguramente si la ciudadanía percibe en un juez esas personalidades débiles, dubitativas o incapaces de hacerse respetar, asociará esas cualidades a la función profesional y sentirá temor de cómo será juzgada su causa si la contraparte es alguien poderoso. A la hora de los test sicológicos o entrevistas para candidatos a jueces aparece esta exigencia como una de aquellas que interesa vislumbrar en qué medida la pueden cubrir si llegan a estar como juez en situaciones riesgosas.

Una vez más recordemos la bifrontalidad de estas exigencias en tanto si bien existe el deber a ser fuerte o valiente (no temerario), también cuenta el destinatario con el

17 Gabaldón López, J., 2003: «Reflexiones sobre la ética judicial», en Ética de las profesiones jurídicas, t. II, Murcia: Universidad Católica San Antonio, p. 795. 
derecho a que se le provea de medios razonables (como por ejemplo de protección policial) a los fines de facilitar o posibilitar el cumplimiento de la misma.

\subsection{Honestidad}

Contemporáneamente el profesional es alguien que cuenta con su profesión para obtener los recursos económicos que necesita para vivir, y precisamente la honestidad tiene que ver con esa legítima posibilidad que reciba lo que le corresponde como retribución de sus servicios. Yendo al juez, la honestidad consiste precisamente en que reciba lo que le corresponde, ni más ni menos; y ello no implica obviamente la alternativa grotesca y delictual de la coima o sus análogos, sino la más sutil que exige que use para la función judicial los bienes o recursos que el Estado o la sociedad han puesto a su disposición. Advirtamos que en cuanto a la alternativa de una prohibición absoluta de utilizar bienes públicos en beneficio privado cualquier ciudadano espontáneamente puede verse inclinado a suscribirla; pero sometida a un control de razonabilidad tal opinión seguramente puede advertirse que resulta exagerada en tanto su seguimiento estricto corre el riesgo de ser más perjudicial que beneficiosa: así por ejemplo no parece inteligente que se prohíba a un juez llamar a su casa para ver cómo sigue su hijo enfermo o que se le impida usar un lápiz o papel para hacer anotaciones particulares. En sintonía con esta preocupación algunos códigos de ética judicial han optado por establecer restricciones de bienes públicos en la medida que resulten "abusivas", "irrazonables" o "desproporcionadas". De todas maneras la idea directriz es que aquellos medios han sido puestos en manos del juez para el cumplimiento de su función y cualquier afectación distinta genera una presunción de falta ética que luego puede llegar a diluirse o justificarse.

En sintonía con el ser y el parecer, como así también con el legítimo control social sobre los funcionarios que la representan o que ejercen el poder que se les ha delegado, aparece la necesidad de efectuar "declaraciones juradas" de bienes que puedan evidenciar la evolución razonable o no sospechosa del patrimonio. No obstante las polémicas suscitadas en torno a dichas declaraciones en cuanto a la resistencia que ha generado en algunos jueces para efectuarla, lo cierto es que los fundamentos para ese rechazo lucen particularmente débiles y exclusivamente argumentados desde el interés personal del mismo juez, pero marginando totalmente los otros intereses o bienes comprometidos y aducidos por los destinatarios de su actividad.

Quizás sea la templanza la vía para vincular esta exigencia ética con el cuadro de virtudes cardinales. Recordemos que aquélla tiene por objeto cierta moderación en la posesión y el uso de bienes externos o aquellos vinculados con el apetito concupiscible. Esa falta de medida propia del "destemplado" termina afectando —advierte Santo Tomás de AQUINO- su «tranquilidad de espíritu» (quies animi) en tanto se compromete el autodominio o deja de ser «dueño de sí mismo» (II-II, 157, 4).

\subsection{Decoro}

Esta palabra se vincula a la arquitectura, más específicamente al ornato en tanto cada profesión tiene un modo de vestir, de hablar, de comportarse, de arreglar el espa- 
cio en donde se presta la profesión, etc. y, en consecuencia, también la actividad judicial tiene un decoro particular. Obviamente que es muy distinto el decoro de un arquitecto, de un encargado de un taller mecánico, de un médico o el del juez, por eso hay cosas que en relación a una de esas profesiones puede resultar decoroso mientras que para otra no lo sea (por ejemplo respecto a la limpieza de la ropa o de las manos, el decorado en las paredes o el estilo lingüístico).

Uno de los problemas implicados en torno al decoro es respecto a la vida privada o no profesional desplegada por el profesional en el espacio público, concretamente si la ética profesional avanza sobre aquélla. El problema, entonces, es si resulta legítimo pretender que el profesional conserve un cierto decoro cuando no presta sus servicios; así, por ejemplo, si la ética le prohíbe que se emborrache en algún bar de su ciudad, que concurra a ciertos lugares donde se practique la prostitución, que forme parte del elenco de un teatro de revistas, que como espectador de un partido de fútbol reaccione descontroladamente insultando o subiéndose al alambrado contra el árbitro o contra el equipo contrario, etc. Al respecto, la línea consolidada en los códigos de ética profesional es que no prescinden de ese espacio en donde no se presta la profesión, y más bien coinciden en avanzar también sobre la vida privada no profesional poniendo normalmente el límite de la "dignidad de la profesión”. Más aún, hay algunas prohibiciones tradicionales en las leyes orgánicas de tribunales que son ejemplo de ello, así la que prohíbe a los jueces a concurrir a salas de juego. Frente al eventual reparo que se puede hacer a esos avances éticos invocando el art. 19 de la Constitución nacional, se responde — entre otras razones- que ahí se habla del ciudadano común que no es asimilable sin más al profesional, dado que éste presta una función pública o un servicio contando para ello con cierto respaldo o monopolio otorgado por la ley, amén de la invocación al orden y a la moral pública.

De todas maneras, el problema más grave es quién fija el contenido del decoro, atento a que podemos encontrarnos con ciertas sociedades dominadas por tradiciones poco racionales que impongan exigencias éticas profesionales inequívocamente contrarias a los derechos naturales o fundamentales; por ejemplo, la prohibición de que las mujeres ejerzan ciertas profesiones con el pretendido fundamento de que no están acordes con su "dignidad". Al respecto las soluciones que se ofrecen a ese problema serían tres: 1 . El decoro lo fijan ciertos ámbitos o sociedades ajenos al lugar donde se presta la profesión pero que se consideran más aptos para establecerlo, por ejemplo atenernos a lo que se piensa en París, la Universidad de Berkeley o San Francisco. 2. El decoro lo establece la sociedad a la que se le presta el servicio y que ha brindado la posibilidad para ello. 3. Se parte del decoro pretendido por la sociedad de ese profesional pero se someten esas exigencias a un control de racionalidad, dado que si bien es legítima aquella primera aproximación, es peligroso un sometimiento dogmático a la misma (pensemos lo que pudo haber establecido respecto a los judíos la ética profesional de la Alemania nazi). Sin duda que esta última propuesta deja un cúmulo de dudas e incertidumbres, pero recordemos que atento a la materia en que estamos no hay posibilidad de encontrar una fórmula inequívoca que permita resolver todas las situaciones y evite la necesidad del juicio racional o prudente en concreto. Para esas inevitables indeterminaciones estarán —entre otros antídotos- un diálogo racional que brinde contenido más concreto al decoro y una apropiada integración y funcionamiento del Tribunal de Ética y de la Comisión de Consultas éticas. 


\subsection{Secreto o confidencialidad}

El profesional, al hilo del servicio que presta, accede a un conocimiento de aspectos variados respecto a su cliente o usuario y, por supuesto, que éste parte de la base que esa información sólo será usada a los fines del mejor trabajo profesional. La ética exige esa reserva y consiguientemente prohíbe que sea difundida deliberadamente o sin propósito alguno a terceros ajenos a la relación profesional; ello reclama del profesional una actitud positiva o activa como para evitar esas infidencias y reaccionar apropiadamente al detectarlas.

La función judicial es fuente de mucha e importante información respecto a las partes, y frecuentemente hay intereses comerciales o de otra índole ansiosos como para obtenerla; por eso la ética exige no sólo que el juez esté consciente de este deber de confidencialidad sino que también lo asuma adoptando medidas eficaces para neutralizar eventuales fugas de información y para investigar o sancionar a los responsables en caso de producirse. Esa exigencia de reserva judicial se extiende a sus familiares, colegas, periodistas, alumnos, etc., o sea, respecto de todos aquellos que resultan terceros en la relación profesional. Los códigos de ética contemplan normalmente situaciones que eximen al profesional de mantener ese secreto profesional, así por ejemplo hablan a los fines de la propia defensa frente a un reclamo o demanda, y también para evitar la comisión de un delito o de un daño.

Para explicar la racionalidad de la presente exigencia hay que recurrir al objeto mismo de la función judicial, pues ésta supone un servicio concreto que se presta a las partes en relación al problema jurídico que las enfrenta y, en consecuencia, rechaza eventuales beneficios -importantes o casi intrascedentes- para el juez en base al uso que pueda hacer de la información obtenida en la tramitación de la causa.

\subsection{Cortesía o afabilidad}

El servicio profesional se presta a un semejante o prójimo, es decir, se canaliza a través de una relación humana en donde está comprometida recíprocamente la dignidad y el respeto de las partes. No hay sometimiento ni subordinación personal alguna, sino más bien una relación que transita en un plano de igualdad intrínseca. Consiguientemente el profesional debe estar dispuesto a brindarle al cliente o usuario las explicaciones o informaciones que oportuna y justificadamente le requiera, y debe hacerlo a través de un trato respetuoso y cortés.

Por supuesto que también sobre el juez pesa esta exigencia en sus relaciones con las partes, abogados, colegas y auxiliares, quien además debe recordar que la autoridad no se construye en base a desplantes, impuntualidades o gritos. Cualquier ciudadano en base a una experiencia humana consolidada puede legítimamente asociar esa beligerancia o indisposición para el trato respetuoso a cierta personalidad desequilibrada o descontrolada incapaz de analizar pausada, racional y dialógicamente los problemas complicados propios de la tarea judicial. La autoridad, preocupada por obtener el mejor premio al que puede aspirar — según Santo Tomás de AQuino—, que es el "afecto", "amistad" o "amor" de los ciudadanos, debe tratarlos del modo idóneo a tales fines, pues sólo un masoquista puede apreciar o respetar a aquel que lo maltrata. 


\subsection{Diligencia}

Todo cliente o usuario pretende que el profesional le preste el servicio en tiempo y forma y que para ello debe poner los medios adecuados y procurar alcanzar el resultado que busca al recurrir a sus servicios. Mirado desde el profesional esta exigencia implica evaluar los medios disponibles para el resultado pretendido, escoger el mejor y esforzarse para conseguirlo. Su obligación es poner los medios para el fin buscado por el cliente, pero no le es indiferente la obtención o no del mismo, pues ello repercutirá directamente a la hora de su responsabilidad.

En el caso del juez su función le impone resolver de la mejor manera y en el menor tiempo posible el problema bajo su jurisdicción, por eso aparece la exigencia de privilegiar el trabajo judicial frente a otros posibles servicios. Se inscribe aquí lo referente a las incompatibilidades laborales del juez, que entre otras razones se justifican para que el juez no distraiga su tiempo en aquello que le es lo más importante. Esas incompatibilidades, más allá de las previsiones legales, tienen esa razón de ser y en consecuencia se tornan plenamente justificadas desde un punto de vista ético cuando el juez no resuelve sus asuntos en tiempo y forma. También aparece aquí la obligación del juez de concurrir a su despacho, especialmente respecto de aquel que lleva el despacho diario, como un modo de "aparecer" o mostrar a los ojos de la sociedad su compromiso con la diligencia.

Es cierto que las leyes orgánicas y también la cultura forense han brindado contenido bastante concreto respecto a la presente exigencia de la diligencia. Así en la provincia de Santa Fe la Ley Orgánica exige a los jueces de primera instancia el concurrir diariamente a su despacho (sin fijarle horarios) y a los camaristas el concurrir el día del acuerdo aunque aquel que lleva el trámite deberá hacerlo diariamente. Seguramente el mejor modo de satisfacer esta exigencia, sin que provoque el reclamo pertinente de los usuarios del servicio, es que efectivamente las decisiones judiciales se produzcan en tiempo y forma oportuna.

\subsection{Transparencia, coherencia o buena fe}

Alguien que mantenga una doble vida, un doble discurso o falte a la correspondencia entre lo que dice y lo que hace, se torna una persona poco confiable con respecto a aquellos con los que trabaja o para aquellos a los que trabaja. Más allá del modo en que efectivamente se preste la profesión, el buen profesional supone y requiere que el cliente o usuario, como así tambien sus auxiliares y colegas, confíen en él de manera que el trabajo, con toda la carga de conexiones, independencia y discreción que encierra inevitablemente, no quede sumido en un marco de desconfianza motivado en aquella falta de transparencia o incoherencia.

En el caso del juez en tanto cabeza de un grupo humano y una tarea que conlleva marcada discreción se torna importante esta exigencia. Para decirlo negativamente, si pensamos en un juez que conduce a sus empleados en base a la mentira, la sospecha, la palabra que no respeta, etc., seguramente le resultará más difícil imponer un espontáneo y confiable seguimiento. Cualquier elemental manual de management y básica experiencia humana confirma cuánto se facilita la dirección de otros en la medida que 
ellos vean coherencia y transparencia. Principalmente los abogados y colegas saben o tienen presente alguna opinión en torno a la presencia o ausencia de esta exigencia ética a la hora de entablar relaciones personales y profesionales, pues se trata de una nota que incide fuertemente en la visión ética de los otros y, por ende, resulta ser favorecedora o entorpecedora de esos contactos.

\subsection{Austeridad republicana}

Es ésta una exigencia que tiene íntima conexión con las circunstancias de tiempo y lugar. Así en la Argentina, en el contexto de las serias dificultades económicas y sociales que ha vivido en estos últimos tiempos, resulta razonable la exigencia prevista en la ley de ética de la función pública de "austeridad republicana" para sus funcionarios. Se trata de que éstos exhiban ciertos bienes externos que guarden correspondencia con el nivel de limitaciones que padece la ciudadanía en general al respecto. Parece poco razonable que haya funcionarios que aparezcan ricos en medio de ciudadanos pobres que, al mismo tiempo y paradojalmente, son los que le pagan mensualmente sus salarios.

Esa exigencia prevista para los funcionarios públicos en general se proyecta innegablemente para los jueces, más aún, la ciudadanía seguramente vería con malos ojos a aquel juez que se preocupa desmedidamente por los bienes externos procurando lucir aquellos que resulten ser los más onerosos. No se trata de deshonestidad dado que puede tratarse de un juez privadamente muy rico, pero lo que se le pide es que a la hora de adquirir bienes procure computar el nivel de problemas económicos y sociales que padece la sociedad a la que les prestará sus servicios judiciales. Incluso puede resultar comprensible que alguien vea en esa restricción algo incompatible con sus gustos y por ende opte por renunciar o no aceptar el cargo de juez. El contenido de esta exigencia tiene esa dimensión histórica que remite a una sociedad particular, por eso no queda sólo librada a la mera conciencia ética del juez implicado.

\subsection{Responsabilidad}

En toda ética profesional se incluye esta exigencia, que implica que el profesional esté dispuesto a "responder" por lo que ha hecho respecto de todos aquellos interesados o implicados - directa o indirectamente - en el trabajo prestado. Es decir, que esta exigencia conlleva que el profesional no eluda, ni transfiera, ni entorpezca ese momento incluido en su servicio en el que deberá brindar explicaciones, pedir disculpas, otorgar reparaciones, aceptar reproches, etc. En el caso del juez es posible discernir distintos ámbitos de la responsabilidad profesional: 1 . Penal: frente al juez competente respecto a su conducta tipificada como delito. 2. Civil: por los daños reclamados por alguna de las partes ante el juez competente. 3. Administrativa o disciplinaria: que discernirá la autoridad administrativa por los incumplimientos a las reglamentaciones administrativas aplicables. 4. Científica o académica: en tanto le corresponde al mundo académico juzgarlo principalmente por medio de críticas o elogios acerca del modo en que operó el Derecho y cómo ha quedado el mismo. 5. Corporativa o colegiada: 
frente a sus colegas y miembros de un eventual Colegio o Asociación de acuerdo a los Estatutos respectivos. 6. Social: respecto a la sociedad en la que presta servicios y la cual lo juzgará por medio de la opinión ciudadana en tanto comprenda y tenga presente sus características, necesidades y pretensiones. 7. Política o constitucional: los otros poderes del Estado, según la distribución efectuada por la Carta Magna, velan por el buen cumplimiento de la función y tienen la competencia de remover al juez en casos graves de incumplimiento. 8. Ética: su objeto es el mejor cumplimiento de la función, por eso, de algún modo, esta responsabilidad es un género en tanto al incurrir el juez en cualquiera de las responsabilidades arriba mencionadas esa falta tiene incidencia sobre esa pretensión del "mejor juez", pero también es una especie de responsabilidad particular o remanente en tanto ante cualquier falta a ese propósito que no aparezca respondida en las anteriores será la responsabilidad ética la que la asuma (por ejemplo, el desorden en el juzgado o cierta descortesía para los abogados) y también puede asumirla si algunos de los interesados en la excelencia judicial encuentran insatisfecha su legítima pretensión al efectivizarse algunas de las otras responsabilidades (por ejemplo, sin perjuicio de la responsabilidad civil o penal puede por el mismo comportamiento delictivo o dañoso exigírsele al juez una responsabilidad ética, pero si hay una remoción por vía de la responsabilidad política pareciera que se agota ya la responsabilidad ética dado que no quedaría remanente en tanto dejara de desempeñarse como juez).

\section{5. ÉTICA DE COMPORTAMIENTOS O ÉTICA DE VIRTUDES}

Las exigencias reseñadas reclaman ciertos comportamientos pero no llegan a pretender necesariamente virtudes. En definitiva, ellas quedan satisfechas si las cumplimos, no obstante que nos falte la intención, la habitualidad y cierto agrado y facilidad. Aunque también es cierto que es probable que a fuerza de reiterar los comportamientos respectivos se llegue a adquirir el hábito de los mismos y, en consecuencia, comiencen a realizarse con "agrado y facilidad". Además, de alcanzarse la virtud, se fortalecen las posibilidades del "mejor" trabajo y las presunciones de que efectivamente se ha hecho "bien" el trabajo. Recordemos que virtud significa fuerza y ellas efectivamente pueden significar una "fuerza" especial que nos inclina al bien. Precisamente ARISTÓtElES reconoce en la adquisición de los hábitos una especie de «segunda naturaleza» que sobreponemos a la dada a cada uno, pues a fuerza de repetir un acto se va arraigando una cierta inclinación y facilidad para hacerlo.

Por otro lado, la obtención de la virtud avanza sobre actos ajenos a la vida profesional que tengan el mismo contenido u objeto, pues sería contradictorio con la afirmación de su existencia si al mismo tiempo decimos que ella se circunscribe a los actos profesionales pero está ausente en los actos no profesionales que también entran en la materia de esa virtud. Así sería casi violatorio del principio lógico de no contradicción afirmar de alguien que es "honesto" o "afable" dentro de tribunales pero al mismo tiempo es "deshonesto" o "descortés" fuera de ese ámbito, y de existir esa persona que "es" y "no es" al mismo tiempo en torno a esa particular virtud lo más probable es que oculte alguna enfermedad psicológica vinculada a personalidades esquizofrénicas o algo parecido. Exigir, en consecuencia, sólo comportamientos buenos o excelentes y no virtudes es plantear exigencias mínimas realistas, aunque una ética de 
máximos o de virtudes será bienvenida y potenciadora de la confianza suscitada en torno a la tarea judicial. Pues la virtud — precisa PIEPER siguiendo al Aquinate- es lo máximo a lo que puede aspirar el hombre (ultimum potentiae) ${ }^{18}$, pero más allá de aspiraciones que es auspicioso que el juez personalmente las asuma, lo que queremos insistir es en exigencias indisponibles para el juez.

Por sobre comportamientos y virtudes nos interesa llamar la atención en torno a que la vida humana no es una mera sumatoria desagregada de actos sino que ella reclama cierta unidad o coherencia. En efecto, la ética desde ARISTÓTELES tiene como objeto material no sólo actos y virtudes sino el ethos, carácter o personalidad moral, o sea aquello que - parafraseando a ARANGUREN — va quedando a medida que va pasando la vida. Por supuesto que mientras dura la vida ella permanece siempre abierta y modificable hasta el momento final o definitivo de la muerte; pero la sucesión de la vida tiende y es saludable que se asuma con un cierto sentido o unidad que permita identificarla con "esa" vida o modo de conducirla. Más correcta y sintéticamente, esos actos, virtudes, talante o pathos configuran una irrepetible vida que asume, principalmente a la mirada de los otros, una cierta personalidad ética o ethos conforme al cual vivimos. En sintonía con LECLERQ, ARANGUREN escribe: «la vida del hombre forma un todo, de tal modo que cada uno de nuestros actos lleva en sí el peso de la vida entera» ${ }^{19}$, y este carácter unitario - aunque siempre cambiante- que procura la vida humana corresponde a lo que los griegos llamaban "bios" que no era simplemente la sucesión de la vida sino ese proyecto vital en donde se insertaban los actos. En definitiva, el "bios" apela a la experiencia humana que nos confirma que la vida moral no es una mera sumatoria desagregada de actos, sino que - no obstante todas las modificaciones que en ella se suceden - ella reclama cierta unidad o coherencia.

Esa riqueza y variedad de la ética profesional en general es puesta de relieve inteligentemente por Andrés OLLERO cuando al respecto distingue tres campos: «el de las exigencias éticas maximalistas destinadas a dar paso a una persona modelo, perfeccionada en el ejercicio de su profesión; el de las exigencias éticas capaces de preservar la confianza de los ciudadanos, mediante el respeto de sus justas expectativas sobre el desenvolvimiento de un razonable modelo profesional; el de las exigencias éticas que, por hallarse más directamente vinculadas a valores y derechos constitucionales, se verían llamadas a gozar de la protección de las normas jurídicas, o incluso la sanción penal» ${ }^{20}$.

\section{CONCLUSIÓN}

La Comisión sobre el "Perfil del Juez" creada en el seno de la Mesa del Diálogo Argentino alcanzó importantes conclusiones ${ }^{21}$, y entre ellas cabe destacar la puntualización que para ser juez se requiere de cuatro idoneidades: la física-sicológica, la téc-

18 PIEPER, J., op. cit., p. 15.

19 Aranguren, J. L., «Ética», Revista de Occidente.

20 Ollero, A., 2003: «Deontología jurídica y derechos humanos», en Ética de las profesiones jurídicas, t. I, Murcia: Universidad Católica San Antonio, p. 65.

21 1958: Realidad Judicial, del 15-8-2003, Madrid: La Ley, Año III, n. 2, p. 378. 
nica-jurídica, la gerencial y la ética. Precisamente ese perfil supone una superación de la mirada tradicional centrada sólo en el conocimiento y las habilidades jurídicas, y remite a un complejo de requerimientos para ejercer la función judicial. Es que, en definitiva, a la sociedad lo que le interesa es contar con "buenos" o los "mejores" jueces, y ésta es una definición que excede a lo jurídico e instala la consideración en el campo de la ética profesional o ética aplicada. Responder a esas exigencias supondrá inevitablemente determinar el fin específico o el bien interno por el que cobra sentido y legitimidad social la actividad judicial, averiguar cuáles son los medios adecuados para generar racionalmente ese bien en la sociedad respecto a la cual hablamos e indagar qué comportamientos, virtudes o personalidad ética se requiere para alcanzar ese bien interno ${ }^{22}$. Pretender sectorizar o reducir aquella preocupación a algunas de las actividades que cumple el juez, como por ejemplo la interpretación jurídica, es ir contra la realidad humana y siglos de experiencia en ese terreno.

${ }^{22}$ Cfr. Cortina, A., y Martínez, E., 1998: Ética, Madrid: Akal, pp. 165 y ss. 